\title{
Behaviour of commercially prepared I-125 fibrinogen in metabolic studies
}

\author{
JANE BRADLEY AND J. A. HICKMAN
}

The London Chest Hospital, E. 2.

SYNOPSIS In-vivo studies of fibrinogen metabolism were carried out using an I-125 labelled preparation of fibrinogen supplied commercially by the Radiochemical Centre, Amersham for use in the diagnosis of deep venous thrombosis. These studies show that the material is suitable for obtaining the main metabolic parameters of clinical interest, though degradation products may be present initially or appear during storage. If suitable corrections are applied the results agree well with those of other authors.

Fibrinogen labelled with $\mathrm{I}-125$ is used clinically in two ways. The first involves injection of labelled material and subsequent external monitoring of radioactivity at the site of interest to detect incorporation of fibrinogen into a blood clot. For example, this technique is used in the diagnosis of deep venous thrombosis (Negus et al, 1968) and in detecting rejection episodes in renal transplant recipients (Salaman, 1972). In the second technique, fibrinogen metabolism is studied by repeated plasma sampling using the labelled fibrinogen as a metabolic tracer. This method has been employed in the elucidation of microangiopathic haemolytic anaemia (Baker et al, 1968), hepatic failure (Flute et al, 1969), and certain types of renal failure (Wardle, 1973). It has also been used to monitor the effects of certain fibrinolytic drugs (Hickman, 1970).

125I-labelled fibrinogen is readily available, for example from the Radiochemical Centre, Amersham, Bucks. This material was developed for fibrinogen monitoring using the first technique but the manufacturers specifically state that it has not been shown to be suitable for the second technique (Radiochemical Centre, 1974). This is because the only requirement for incorporation into a clot is the clottability of the fibrinogen while a true metabolic tracer must behave in exactly the same way as the material being studied.

When Amersham fibrinogen was first introduced, it was used for metabolic studies (Jeyasingh et al, 1970; Hickman, 1971; Wardle, 1973) and the results agreed well with those obtained with freshly-

Received for publication 7 January 1975. prepared fibrinogen (Takeda, 1966). However, the manufacturing process was altered in view of the risk of transmission of viral hepatitis (Zuckerman, et al, 1971), and subsequently the metabolic handling of the material deteriorated (Hickman, unpublished work). The present preparation of ${ }^{125}$ I fibrinogen has been available since 1972 (Gravett, 1974, personal communication) but no reports have been made so far on its metabolic behaviour.

In view of the problems attached to the separation and iodination of fibrinogen under sterile conditions in the laboratory, it is obviously more convenient to use a manufactured preparation if this is suitable. As part of a continuing study into certain haematological aspects of respiratory failure, the metabolic behaviour of Amersham fibrinogen was fully investigated in a small number of human subjects.

\section{Materials and Methods}

\section{I-LABELLED FIBRINOGEN}

The labelled fibrinogen was provided by the Radiochemical Centre, Amersham, Bucks from their routine stock. The fibrinogen, from donors rigorously screened for hepatitis, is prepared by precipitation and stored by freeze-drying (British Pharmacopoeia, 1973) until iodination using a strictly controlled modification (Gravett, 1974) of the chloramine-T method (Greenwood et al, 1963).

The material is supplied in ampoules containing not more than $1.2 \mathrm{mg}$ of iodinated fibrinogen which is reconstituted with sterile water. The radioactivity injected is approximately $100 \mu \mathrm{Ci}$, depending on the time from iodination. This material is claimed 
to remain suitable for detection of deep-vein thrombosis for a period of six weeks from manufacture.

Five different fibrinogen batches were used and have been numbered in sequence. For each batch there was an inevitable delay of eight days between iodination and injection due to sterility checks after manufacture, packaging, and dispatch procedures. The fibrinogen was stored after receipt below $-20^{\circ} \mathrm{C}$ for periods of up to 92 days from iodination before reconstitution and immediate injection.

\section{SELECTION OF SUBJECTS}

Eighteen subjects were investigated and all gave their informed consent to undergo the study. This total consisted of nine patients with respiratory failure, as defined by the usual blood gas criteria (Campbell, 1965), two with myocardial infarction, and seven healthy controls. Three of the patients were simultaneously screened for deep-vein thrombosis (Negus et al, 1968) with negative results. With one exception (BF, aged 36) the patients were aged between 50 and 65 years, while the controls were men between 25 and 35 years.

\section{PROCEDURE}

Thyroid uptake of radioactive iodine was blocked by the oral administration of $150 \mathrm{mg} \mathrm{KI}$ daily for 48 hours before and for 10 days after injection of the labelled fibrinogen. Samples of venous blood were taken 15 minutes after injection, at least twice more on the first day, and then once or twice daily for seven to 10 days.

PLASMA RADIOACTIVITY

The method was that of Regoeczi (1967) as modified by Hickman (1971). The radioactivity in the samples was measured in a well-type scintillation counter $\vec{F}$ before (count I) and after (count II) removal of the fibrin clot with a stainless steel needle. The activity in the clottable fraction of the plasma was $\frac{\bar{\sigma}}{\overline{0}}$ represented by count $I$ - count II and the $\overrightarrow{\mathbb{D}}$ percentage clottability of the preparation by $\frac{\circ}{0}$ $\frac{\text { Count I-Count II }}{\text { Count II }} \times 100$. The mean percentage $\vec{\circ}$ error in the clottable radioactivity of 50 randomly $\overrightarrow{\vec{\omega}}$ selected pairs of duplicate samples was $1.7 \% \frac{\text { 응 }}{2}$ (range $0 \cdot 2-4 \cdot 9 \%$ ).

125I fibrinogen survival was obtained from serial ${ }_{\infty}^{\text {i }}$ studies of the activity in the 'clottable' fraction of $\%$ the plasma. All values after the initial 15-minute $\stackrel{p}{\infty}$ estimation were expressed as a percentage of the ${ }^{2}$ initial value, and the results were plotted graphically 운 on a log-linear scale. The results were analysed according to the compartmental model of Matthews (1957).

\section{Results}

IN-VIVO CLOTTABILITY

The average clottability, defined as the mean of all clottability measurements for a given subject, remained between $87 \%$ and $96 \%$ (see table I, column 7). Figure 1 shows how the clottability of the 15-minute sample varied with time after iodination for different batches. It is evident that the $\frac{\circ}{3}$ clottability varied from batch to batch, but the samples used within 24 days of iodination had a higher clottability than the older samples. Figure 2 shows the day-to-day variation of clottability? for individual subjects after injection, and measurements are shown for two different batches.

\begin{tabular}{|c|c|c|c|c|c|c|c|c|c|c|c|c|}
\hline \multirow[t]{2}{*}{ Subject } & & \multirow[t]{2}{*}{ Sex } & \multirow[t]{2}{*}{ Batch No. } & \multirow[t]{2}{*}{$A g e^{1}$} & \multirow{2}{*}{$\begin{array}{l}\text { Half-life } \\
T_{\frac{1}{2}} \text { (days) }\end{array}$} & \multirow{2}{*}{$\begin{array}{l}\text { Average } \\
\text { Clottability } \\
(\%)\end{array}$} & \multicolumn{3}{|c|}{ Intercepts } & \multicolumn{3}{|c|}{ Rate Constants } \\
\hline & & & & & & & $C_{1}$ & $C_{2}$ & $C_{2}$ & $b_{1}$ & $b_{\mathbf{a}}$ & $b_{3}$ \\
\hline JS & $\mathbf{P}$ & $\mathbf{M}$ & 1 & 9 & $3 \cdot 1$ & - & 46 & 30 & 24 & 0.22 & $1 \cdot 36$ & 7 \\
\hline TH & C & $\mathbf{M}$ & 1 & 78 & 4.0 & 87 & 38 & 32 & 30 & $0 \cdot 17$ & $1 \cdot 5$ & 14 \\
\hline LS & $\mathbf{P}$ & $\mathbf{M}$ & 1 & 78 & 3.6 & 89 & 40 & 35 & 25 & 0.19 & $1 \cdot 36$ & 14 \\
\hline $\mathrm{CC}$ & $\mathbf{P}$ & $\mathbf{M}$ & 1 & 92 & 3.8 & 88 & 35 & 34 & 31 & 0.18 & 1.66 & 13 \\
\hline BF & $\mathbf{P}$ & $\mathbf{M}$ & 1 & 92 & 4.8 & 85 & 30 & - & - & $0 \cdot 14$ & - & - \\
\hline JH & C & $\mathbf{M}$ & 2 & 10 & $5 \cdot 1$ & 94 & 62 & 38 & - & 0.14 & 1.67 & - \\
\hline DM & $\mathbf{P}$ & $\mathbf{M}$ & 2 & 10 & 5.0 & 95 & 76 & 24 & - & $0 \cdot 14$ & 1.67 & - \\
\hline MJ & C & $\mathbf{M}$ & 2 & 23 & 4.5 & 94 & 57 & 43 & - & 0.15 & $2 \cdot 00$ & - \\
\hline $\mathbf{M F}$ & C & $\mathbf{M}$ & 2 & 69 & 4.5 & 92 & 35 & 27 & 38 & 0.51 & 0.91 & 7 \\
\hline $\mathbf{L T}$ & $\mathbf{P}$ & $\mathbf{F}$ & 3 & 12 & 3.0 & 94 & 63 & 37 & - & 0.23 & $2 \cdot 25$ & - \\
\hline TF & C & $\mathbf{M}$ & 3 & 12 & $3 \cdot 5$ & 95 & 68 & 32 & - & $\mathbf{0 . 2 0}$ & $4 \cdot 35$ & - \\
\hline LH & $\mathbf{P}$ & $\mathbf{F}$ & 3 & 16 & $3 \cdot 1$ & 94 & 62 & 38 & - & $0 \cdot 22$ & 1.67 & - \\
\hline DE & C & $\mathbf{M}$ & 4 & 10 & 3.9 & 96 & 71 & 29 & - & 0.18 & $1 \cdot 54$ & - \\
\hline CB & $\mathbf{P}$ & $\mathbf{M}$ & 4 & 11 & 3.8 & - & 59 & 41 & - & 0.18 & $1 \cdot 58$ & - \\
\hline CS & $\mathbf{P}$ & $\mathbf{M}$ & 4 & 12 & 3.8 & - & 63 & 37 & - & 0.18 & 1.05 & - \\
\hline $\mathbf{H P}$ & $\mathbf{P}$ & $\mathbf{M}$ & 5 & 19 & 4.8 & 96 & 76 & 24 & - & 0.14 & 0.91 & - \\
\hline AD & C & $\mathbf{M}$ & 5 & 24 & $3 \cdot 7$ & 96 & 76 & 24 & - & 0.19 & $2 \cdot 50$ & - \\
\hline ET & $\mathbf{P}$ & $\mathbf{F}$ & 5 & 24 & 3.4 & 96 & 70 & 30 & - & $0 \cdot 20$ & $2 \cdot 50$ & - \\
\hline
\end{tabular}

Table I Plasma clottable radioactivity: results for patients and controls 


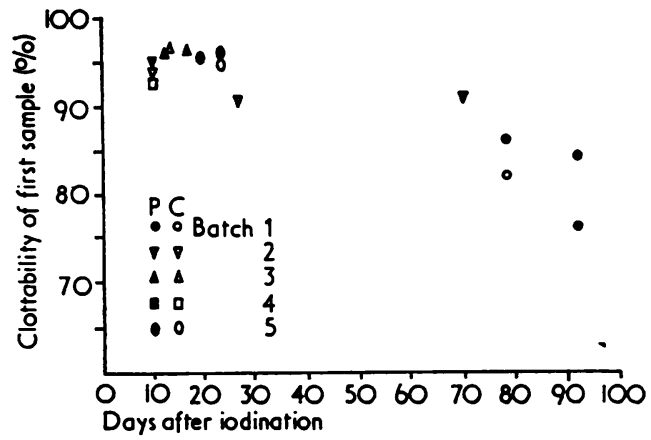

Fig 1 Clottability of first sample (\%) as a function of time since iodination (days) for different batches.

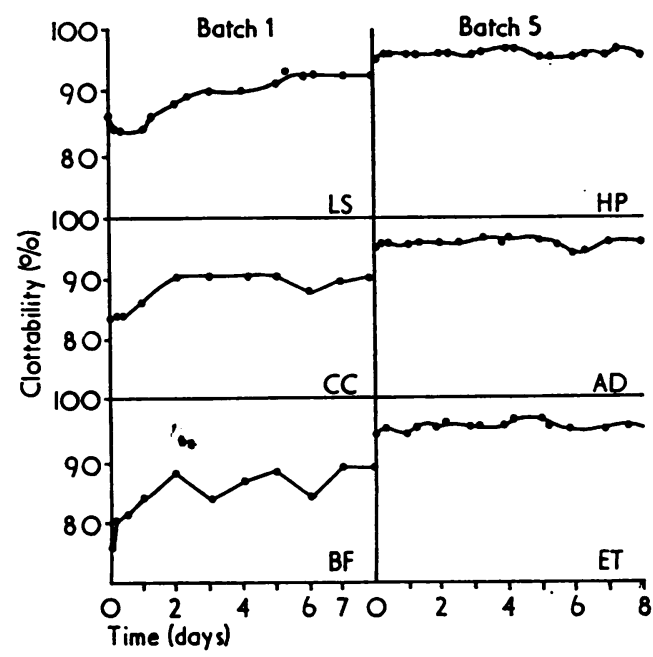

Fig 2 Variation of in-vivo clottability $(\%)$ with time after injection (days) for different batches.

\section{FIBRINOGEN SURVIVAL}

Table I summarizes the results. It was found that, when plotted graphically on a log-linear scale, some of the curves depicting the decline in the clottable radioactivity of the plasma could be analysed into two exponentials and others into three exponentials. The simpler method of visual curvefitting was used in preference to a computer analysis because Tytgat has shown the two methods to be comparable in accuracy (Tytgat, 1971; Collen et al, 1972).

Figures 3 and 4 are representative of the two types of curve. In fig 3 the clottable radioactivity, shown by the solid line, can be described accurately by the sum of two exponentials with intercepts

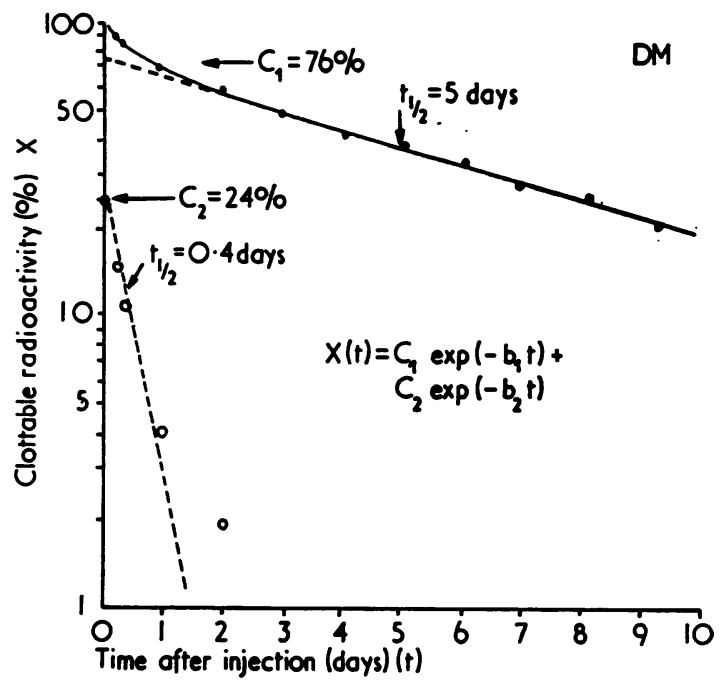

Fig 3 Variation of clottable radioactivity (\%) with time after injection (days) for subject DM. Analysis into the sum of two exponentials.

$C_{1}$ and $C_{2}$ and rate constants $b_{1}$ and $b_{2}$ respectively In fig 4 the curve is described by the sum of three exponentials, with intercepts $C_{1}, C_{2}$, and $C_{3}$ and rate constants $b_{1}, b_{2}$, and $b_{3}$ respectively. Table I lists these parameters for the 18 subjects. The half-life ( $\left.\mathrm{T} \frac{1}{2}\right)$ of the slowest decaying component is also listed.

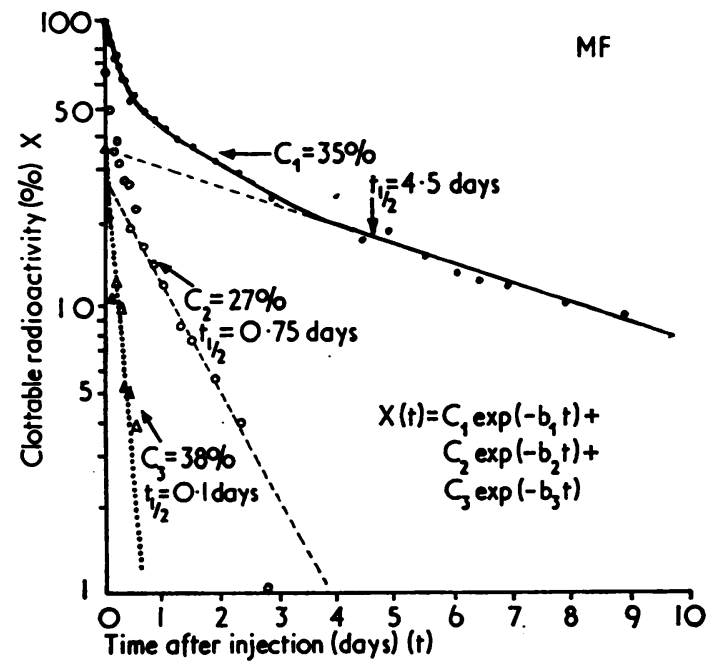

Fig 4 Variation of clottable radioactivity ( $\%$ with time after injection (days) for subject MF. Analysis into the sum of three exponentials. 
Discussion

COMPARTMENTAL ANALYSIS

Freshly iodinated 125I fibrinogen, injected into healthy subjects, gives rise to plasma clottable radioactivity curves which are best described by the sum of two exponentially decaying components: $C_{1} \exp \left(-b_{1} t\right)+C_{2} \exp \left(-b_{2} t\right)-$ see fig 3. Matthews (1957) has shown that a plasma radioactivity curve of this form can be explained in terms of a threecompartment model. This model describes the interchange of fibrinogen between the plasma and an extravascular compartment, combined with catabolism and excretion of fibrinogen into the urine. Atencio et al (1965) have described a more complicated model along similar lines. The appearance of a third exponential in the plasma radioactivity curve, as in certain of the studies shown in table $I$, can be attributed either to the presence of a fourth compartment (Matthews, 1957) or to the existence of separately metabolized components in the nominally pure fibrinogen (Regoeczi, 1971). The latter explanation is more likely in view of the effect of sample age.

CHANGE IN DECAY CURVES WITH SAMPLE AGE Stored fibrinogen can be expected to deteriorate slowly (Regoeczi and Stannard, 1969; Radiochemical Centre, 1974). The appearance of a third exponential in the decay curve in experiments using stored fibrinogen might therefore be attributed to this deterioration rather than to the presence of an additional compartment. Using fibrinogen stored for periods in vitro before iodination, Regoeczi and Stannard (1969) showed that the clottable radioactivity consisted of a small fraction (5-6\%) which disappeared rapidly from the plasma while the remainder behaved as metabolically normal fibrinogen. The results of the present study are consistent with this interpretation but the rapidly catabolized fraction reached, in certain cases, values of $30 \%$ or greater (see fig 4 ).

In some cases the very rapid disappearance of the third exponential could not be observed directly because of the limited number of data points. Its existence, however, could be inferred from a lowering of the intercept $\mathrm{C}_{1}$ of the slow component. Fig 5 demonstrated the relationship between the intercept $C_{1}$ and the age of the fibrinogen. 'Old' material (more than 60 days after iodination) produced a clearly marked third exponential which (with one exception-JS) was not seen in recently iodinated material. As the material aged,'the intercept $C_{1}$ decreased even before a third exponential could be distinguished. This decrease is presumably due to an increasing degradation with time, while

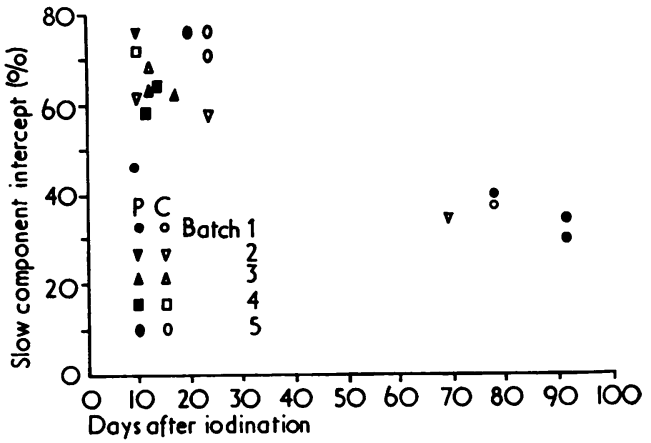

Fig 5 Distribution of the slow component intercept $C_{1}$ (\%) with time since iodination (days) for different batches.

the initial scatter of $\mathrm{C}_{1}$ may be due to manufacturing $\vec{c}$ variation. The results of JS suggest that some degradation had occurred in that batch despite $\overparen{\Phi}$ freshness of the material. Nevertheless the purity $\overrightarrow{0}$ of the fibrinogen, as measured by clottability, $v$ remained high, and the metabolic rate constant, calculated after correction (vide infra) using the three-compartmental model, was in agreement with the results of other authors.

\section{EFFECT OF SAMPLE AGE ON CLOTTABILITY}

The difference between apparently pure and partially음 degraded fibrinogen samples can be seen in an effect on the clottability as well as in the appearance of a third exponent in the plasma radioactivity curve. If clottability is plotted against time after injection, a difference can be seen between storedoand newly iodinated samples (see fig 2). In an attempt to quantify this variation, the average rate of change of clottability with time during the first 48 hours after injection ('initial clottabilityo change'-in percent/day) was measured for each $_{\supset}$ subject and plotted as a function of the slow component intercept $C_{1}$. Fig 6 shows that a near-linear relationship exists between these two parameters. for almost all the subjects examined. Since $\mathrm{C}_{1} \mathrm{~N}$ has been shown to decrease with sample age, NN initial clottability must also decrease with sampleog age, confirming the hypothesis of gradual inacti vation of the fibrinogen.

Animal experiments by Regoeczi (1967) have suggested that an initial clottability rise is to be expected even with material of reasonably highō clottability (for example, greater than 93\%). This initial rise can be explained in terms of differencess in diffusing ability between the fibrinogen and the inevitable small amount of contaminating protein. This rise is still present in material showing threeo 


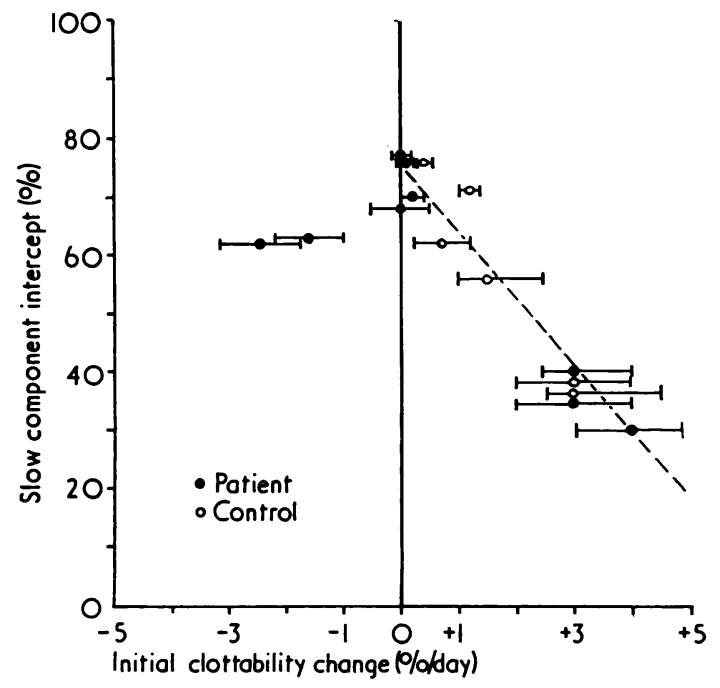

Fig 6 Relation between initial clottability change (percent per day) and slow component intercept $C_{1}(\%)$.

exponentials on the plasma clottable radioactivity curve. Thus it appears that the degradation products, whatever their nature, are still clottable but have a higher diffusing ability than 'pure' fibrinogen because they rapidly disappear from the plasma curve. It can be seen from fig 6 that two of the patients showed an initial decrease in clottability which might be explained by the presence of an undiagnosed deep-vein thrombosis or other fibrinogen-consuming site.

\section{METABOLIC RATE CONSTANTS}

The metabolic rate constants which can be calculated from the three-compartment model are the fractional catabolic rate $\left(\mathrm{K}_{12}\right)$, the fractional transcapillary transfer or efflux rate $\left(\mathrm{K}_{13}\right)$, and the fractional transcapillary reflux rate $\left(\mathrm{K}_{31}\right)$ (Matthews, 1957). Table II lists these parameters for 17 of the 18 subjects: the experimental scatter for one patient (BF) was too large to permit calculation of the parameters. For those subjects whose graph of clottable radioactivity against time showed a third exponential component, the intercepts $C_{1}$ and $C_{2}$ were modified to $\mathrm{C}_{1}{ }^{\prime}$ and $\mathrm{C}_{2}{ }^{\prime}$ :

$$
\begin{aligned}
& \mathrm{C}_{1}{ }^{\prime}=\mathrm{C}_{1} /\left(\mathrm{C}_{1}+\mathrm{C}_{2}\right) \\
& \mathrm{C}_{2}{ }^{\prime}=\mathrm{C}_{2} /\left(\mathrm{C}_{1}+\mathrm{C}_{2}\right)
\end{aligned}
$$

and the modified values were used in the analysis instead of $C_{1}$ and $C_{2}$. This correction is necessary to eliminate the effect of the third component, which plays no part in the fibrinogen metabolism and only acts as a contaminant.

A systematic dependence of the rate constants on the purity of the material, as measured by the intercept $C_{1}$, might be expected $a$ priori. This is because it is possible to show from Matthews' analysis that, for example, the change $\mathrm{dK}_{12}$ in the parameter $K_{12}$ due to a changed $C_{1}$ in the intercept $\mathrm{C}_{1}$ is given by

$$
\mathrm{dK}_{12}=-\left(\mathrm{K}_{12}\right)^{2} \cdot \mathrm{dC}_{1} / \mathrm{b}_{1} \text {. }
$$

Thus, taking typical values (Tytgat, 1971) of $\mathrm{K}_{12}=$ $0.24, C_{1}=0.67$, and $b_{1}=0.17$, a $20 \%$ decrease in $\mathrm{C}_{1}$ (from $67 \%$ to $54 \%$ ) produces a $19 \%$ increase in $\mathrm{K}_{12}$ (from 0.24 to 0.295 ). This anticipated systematic dependence of the rate constants is not evident in fig 7, which shows the rate constants obtained in the present study plotted against the slow-component intercept $\mathbf{C}_{1}$. The horizontal dotted lines depict the upper and lower limits ( \pm 1 standard deviation) to the range calculated by Tytgat (1971). The normal ranges for $K_{12}$ and $K_{13}$ calculated by Takeda (1966) are very similar.

It is clear that the rate constants calculated for the control subjects in the present study agree well with Tytgat's and Takeda's values. Table III lists the average values and standard deviations for $K_{12}, K_{13}$, and $K_{31}$ obtained in the present study and by previous authors. The difference in value for $K_{31}$ between Tytgat and the present study (1.02 against $1.33)$ is due entirely to the value of 2.99 obtained from one control (TF). This unusually high value for the reflux rate constant appears to be genuine and is associated with a high value for $K_{13}$.

The other parameters listed in table III are the half-life $\left(\mathrm{T}_{2} \frac{1}{2}\right)$ and the slow-component intercept $\mathrm{C}_{1}$. Because the half-life of the plasma radioactivity

\begin{tabular}{|c|c|c|c|c|c|c|c|c|c|c|c|c|c|c|c|c|c|}
\hline & \multicolumn{17}{|c|}{ Subject } \\
\hline & $J S$ & $T H$ & $L S$ & $C C$ & $J H$ & $D M$ & $M J$ & $M F$ & $L T$ & $T F$ & $L H$ & $D E$ & $C B$ & $C S$ & $H P$ & $A D$ & $E T$ \\
\hline $\begin{array}{l}\text { Patient/control } \\
\mathbf{K}_{31} \\
\mathbf{K}_{12} \\
\mathbf{K}_{13}\end{array}$ & $\begin{array}{l}P \\
0.91 \\
0.33 \\
0.34\end{array}$ & $\begin{array}{l}\text { C } \\
0.89 \\
0.29 \\
0.49\end{array}$ & $\begin{array}{l}P \\
0 \cdot 81 \\
0.32 \\
0.42\end{array}$ & $\begin{array}{l}P \\
0.94 \\
0.32 \\
0.62\end{array}$ & $\begin{array}{l}C \\
1.09 \\
0.21 \\
0.51\end{array}$ & $\begin{array}{l}P \\
1 \cdot 29 \\
0 \cdot 18 \\
0 \cdot 34\end{array}$ & $\begin{array}{l}C \\
1.20 \\
0.26 \\
0.69\end{array}$ & $\begin{array}{l}C \\
0.58 \\
0.23 \\
0.25\end{array}$ & $\begin{array}{l}P \\
1 \cdot 50 \\
0.33 \\
0.65\end{array}$ & $\begin{array}{l}C \\
2 \cdot 99 \\
0 \cdot 28 \\
1 \cdot 26\end{array}$ & $\begin{array}{l}P \\
1 \cdot 12 \\
0 \cdot 32 \\
0 \cdot 45\end{array}$ & $\begin{array}{l}C \\
1 \cdot 15 \\
0 \cdot 24 \\
0 \cdot 33\end{array}$ & $\begin{array}{l}P \\
1.01 \\
0.29 \\
0.47\end{array}$ & $\begin{array}{l}P \\
0 \cdot 70 \\
0 \cdot 27 \\
0 \cdot 26\end{array}$ & $\begin{array}{l}P \\
0 \cdot 72 \\
0 \cdot 18 \\
0 \cdot 15\end{array}$ & $\begin{array}{l}\mathrm{C} \\
1.45 \\
0.25 \\
0.29\end{array}$ & $\begin{array}{l}P \\
1 \cdot 01 \\
0 \cdot 27 \\
0.62\end{array}$ \\
\hline
\end{tabular}
curve bears an approximately inverse relationship to the fibrinogen catabolic rate and is an easily

Table II Metabolic parameters for patients and controls in the present study 


\begin{tabular}{|c|c|c|c|c|c|c|}
\hline Author & No. studied & $T \frac{1}{\mathrm{~g}}($ days $)$ & $C_{1}$ & $K_{31}(/ d a y)$ & $K_{12}(/$ day $)$ & $K_{12}(/ d a y)$ \\
\hline Takeda (1966) & 12 & $\begin{array}{r}3.36 \\
\pm 0.25\end{array}$ & $\begin{array}{r}0.82 \\
\pm 0.02\end{array}$ & - & $\begin{array}{r}0.246 \\
\pm 0.016\end{array}$ & $\begin{array}{r}0.548 \\
\pm 0.309\end{array}$ \\
\hline $\begin{array}{l}\text { Regoeczi and } \\
\text { Stannard (1969) }\end{array}$ & 1 & 3.90 & - & - & - & - \\
\hline Hickman (1971) & $13^{1}$ & $\begin{array}{r}4.00 \\
\pm 0.54\end{array}$ & $\begin{array}{r}0.77 \\
\pm 0.09\end{array}$ & - & $\begin{aligned} & 0.225 \\
\pm & 0.02\end{aligned}$ & - \\
\hline Tytgat (1971) & 35 & $\begin{array}{r}4 \cdot 14 \\
\pm 0.56\end{array}$ & $\begin{array}{r}0.67 \\
\pm 0.08\end{array}$ & $\begin{array}{r}1.02 \\
\pm 0.39\end{array}$ & $\begin{array}{r}0.24 \\
\pm 0.04\end{array}$ & $\begin{array}{l}0.60 \\
0.26\end{array}$ \\
\hline Present study & 7 & $\begin{array}{r}4 \cdot 17 \\
\pm 0.55\end{array}$ & $\begin{array}{r}0.64 \\
\pm 0.08\end{array}$ & $\begin{array}{r}1 \cdot 33 \\
\pm 0.70\end{array}$ & $\begin{array}{r}0.25 \\
\pm 0.03\end{array}$ & $\begin{array}{r}0.55 \\
\pm 0.33\end{array}$ \\
\hline
\end{tabular}

Table III Metabolic parameters of healthy subjects: comparison with previous studies

${ }^{1}$ Contrast group of patients
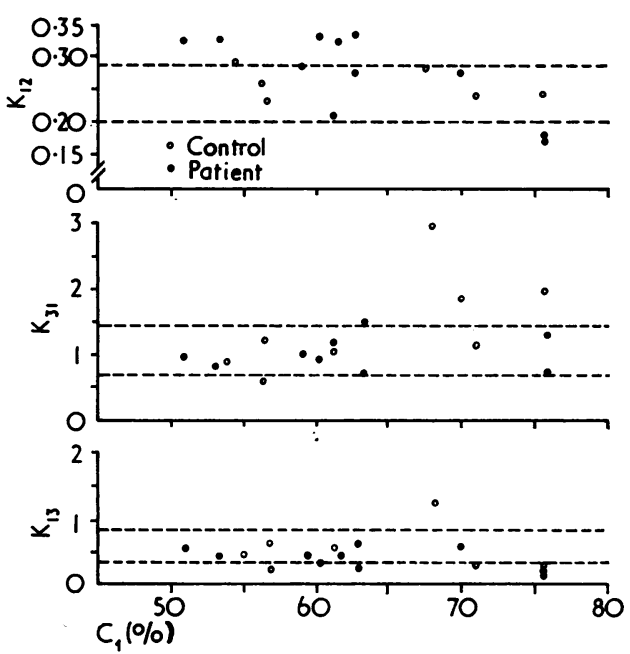

Fig 7 Metabolic rate constants versus intercept $C_{1}(\%)$.

obtained measurement requiring no calculation, it is the most frequently quoted parameter in studies of fibrinogen metabolism. It can be seen in the table that the present study shows values for $T \frac{1}{2}$ which are consistent with those of other authors, although Takeda's value (1966) is much lower. There seems to be some correlation between the intercept $\mathrm{C}_{1}$ and the half-life. The highest value of $\mathbf{C}_{1}$ is associated with the shortest half-life and vice-versa.

It is worth noting that the 'double-half-life' phenomenon described by Regoeczi (1971) was not observed in this study, although the effect is reported to be more frequent in improperly stored or overstored preparations. As described, this phenomenon takes the form of a sudden change in the slope of the plasma clottable radioactivity curve with an apparent abrupt change in the half-life. Regoeczi attributes this to a genuine change in the catabolic rate constant and has put forward two possible explanations which are hypotheses related to the metabolic behaviour of the reticulo-endotheliapo cells. Nevertheless the similarity between fig 4 (whicho was analysed into the sum of three exponentials) and Regoeczi's illustrative example is quite striking. It is probable that some of the apparent observations of this effect may be the result of small numbers of samples, combined with the effects of random errors.

In conclusion it appears that ready-prepared 125I fibrinogen, at least from this source and when used within four weeks of iodination, is adequateo for obtaining data on fibrinogen metabolism气 Nevertheless Regoeczi's comments $(1967,1971) \mathbb{Q}$ regarding the desiraibility of using freshly prepared and iodinated fibrinogen for metabolic studies 5 still remain valid.

Our thanks are due to Mr. G. Marlow of the Radio chemical Centre, Amersham for supplying the material, to Mr. M. R. B. Forshaw for mathematicaß assistance, and to Dr. L. H. Capel for allowing us to study patients under his care. We also gratefully? acknowledge financial support from The London Hospital and the Cardiovascular Institute, The Brompton Hospital.

\section{References}

Atencio, A. C., Bailey, H. R., and Reeve, E. B. (1965)? Studies on the metabolism and distribution of fibrinogen in young and older rabbits. I. Methods and models. J. Lab. clin. Med., 66, 1-19.

Baker, L. R. I., Rubenberg, M. L., Dacie, J. V., and Brain, M. C. (1968). Fibrinogen catabolism in microangiopathio $\mathbb{D}$ haemolytic anaemia. Brit. J. Haemat., 14, 617-625.

British Pharmacopoeia (1973). Dried human fibrinogen fort isotopic labelling, in British Pharmocopoeia, 1973, pp 66-67. HMSO, London.

Campbell, E. J. M. (1965). Respiratory failure. Brit. med. J., 1, 1451-1460.

Collen, D., Tytgat, G. N., Claeys, H., and Piessens, R. (1972). Metabolism and distribution of fibrinogen. I. Fibrinogen turnover in physiological conditions inf humans. Brit. J. Haemat., 22, 681-700. 
Flute, P. T., Rake, M. O., Williams, R., Seaman, M. J., and Calne, R. Y. (1969). Liver transplantation in man. IV. Haemorrhage and thrombosis. Brit. med. J., 3, 20-23.

Gravett, D. (1974). Radiochemical Centre, Amersham. (Personal communication).

Greenwood, F. C., Hunter, W. M., and Glover, J. S. (1963). The preparation of ${ }^{131}$ I-labelled human growth hormone of high specific radioactivity. Biochem. J., 89, 114-123.

Hickman, J. A. (1970). Pharmacological enhancement of fibrinolytic activity and ${ }^{125}$ I-fibrinogen survival. J. clin. Path., 23, 797-800.

Hickman, J. A. (1971). A study of the metabolism of fibrinogen after surgical operations. Clin. Sci., 41, 141-152.

Jeyasingh, K., Maurer, B., Rosengarten, D. S., and Verma, T. R. (1970). Decline in blood activity of ${ }^{125}$ I-fibrinogen in venous thrombosis. Lancet, 2, 294-296.

Matthews, C. M. E. (1957). The theory of tracer experiments with ${ }^{131}$ I-labelled plasma proteins. Phys. in Med. Biol., 2, 36-53.

Negus, D., Pinto, D. J., Le Quesne, L. P., Brown, N., and Chapman, M. (1968). ${ }^{125}$ I-labelled fibrinogen in the diagnosis of deep-vein thrombosis and its correlation with phlebography. Brit. J. Surg., 55, 835-839.

Radiochemical Centre, Amersham, Data Sheet. (1974). Iodinated $\mathrm{I}^{125}$ human fibrinogen injection.
Regoeczi, E. (1967). Measuring the coagulability of fibrinogen in plasma by isotopic means: method and principles of its use for in vivo studies. Thromb. Diathes. Haemorrh. (Stuttg.), 18, 276-285.

Regoeczi, E. (1971). Iodine-labelled fibrinogen: a review. Brit. J. Haematol., 20, 649-663.

Regoeczi, E. and Stannard, B. A. (1969). In vivo behaviour of frozen and freeze-dried fibrinogen and of that prepared from out-dated blood. Biochem. biophys. Acta, 181, 287-294.

Salaman, J. R. (1972). A technique for detecting rejection episodes in human transplant recipients using radioactive fibrinogen. Brit. J. Surg., 59, 138-124,

Takeda, Y. (1966). Studies of the metabolism and distribution of fibrinogen in healthy men with autologous ${ }^{125}$ I-labeled fibrinogen. J. clin. Invest., 45, 103-111.

Tytgat, G. N. (1971). Metabolism and distribution of fibrinogen in clinical and experimental conditions. Thesis-University of Louvain.

Wardle, E. N. (1973). Fibrinogen catabolism studies in patients with renal disease. Quart. J. Med., 42, 205-219.

Zuckerman, A. J., Taylor, P. E., Bird, R. G., and Russell, M. (1971). The Australia (hepatitis-associated) antigen in fibrinogen and other fractions of human plasma. J. clin. Path., 24, 2-7. 